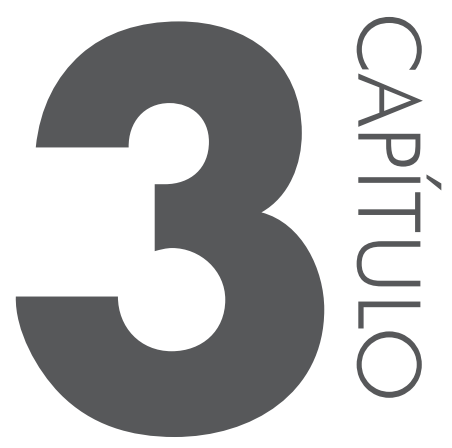

\title{
Dispositivos móveis em ambientes didáticos
}

Marcelo Fernandes Pereira, Doutor, Pontifícia Universidade Católica do Rio de Janeiro (PUC-Rio)

\section{INTRODUÇÃO}

O acelerado progresso tecnológico em que estamos inseridos nos apresenta novas possibilidades de colaboração interpessoal. Pesquisar, criar, catalogar, armazenar e compartilhar dados são atividades frequentes em nosso dia a dia - dos primeiros computadores portáteis aos celulares inteligentes dos dias de hoje, chegamos a uma realidade onde nossa preocupação não está mais no meio físico de armazenamento das informações, mas em como acessá-las e compartilhá-las de modo eficiente e seguro sempre que necessário.

É neste cenário que os atuais alunos de nossas escolas e universidades estão inseridos. Em seus cotidianos, estão acostumados a utilizar seus dispositivos móveis para compartilhar uma grande variedade de informações com amigos e familiares; e, em seus futuros profissionais, muitos trabalharão diariamente com ferramentas colaborativas digitais. 
Os estudantes de hoje convivem com uma gama variada de tecnologias de comunicação digital, a partir da qual ferramentas que eram consideradas mera curiosidade passaram a fazer parte de nosso cotidiano. Gradativamente, essas ferramentas estão migrando da esfera do lazer para o ambiente profissional, otimizando os trabalhos colaborativos de um modo sem precedentes em nossa história.

Entretanto, as metodologias de ensino habitualmente aplicadas no ambiente educacional não acompanharam o avanço das tecnologias de informação. Ainda é raro encontrarmos alunos orientados a aplicar em suas atividades acadêmicas os recursos oferecidos pelos serviços e equipamentos que utilizam em atividades de lazer e socialização.

Ao avaliar o uso de tecnologia como ferramenta educacional para adultos, a pedagoga Andrea Filatro questiona, de modo geral, a relação entre o planejamento das atividades acadêmicas e a ineficiência do uso de tecnologia no ensino:

Se a tecnologia vem para enriquecer e facilitar o processo de ensino-aprendizagem, e se os adultos são capazes, por si sós, aproveitar essas facilidades em sua prática profissional, nas atividades de lazer e até nas relações humanas mais íntimas, que fatores produzem índices tão críticos em se tratando de tornar a educação mais eficaz? E mais, se a tecnologia é boa para o trabalho, para a pesquisa, para o desenvolvimento de comunidades, para conhecer pessoas, e se os adultos são autônomos para utilizá-la em seu proveito das formas mais criativas possíveis, o gargalo está na maneira de planejar a utilização desta tecnologia para fins educacionais? (2004, p. 19)

Filatro sugere o estudo da relação entre as tecnologias de informação e os métodos de ensino como forma de revitalizar a educação contemporânea:

Compreender de que forma as tecnologias de informação e comunicação contribuem para o aperfeiçoamento do processo de ensino-aprendizagem representa uma oportunidade de redescobrir a natureza ímpar, insubstituível e altamente criativa da educação no processo de desenvolvimento humano e social (2004, p. 32).

Em uma realidade onde os jovens permanecem em contato constante uns com os outros através de seus smartphones, as teorias de inteligência coletiva tornam-se cada vez mais palpáveis. Ao mesmo tempo, os métodos de ensino convencionais mostram-se pouco eficientes na preparação dos alunos para o aspecto prático da vida profissional. Projetos são desenvolvidos por um número crescente de mentes trabalhando em conjunto, conectadas através de redes digitais cada vez mais eficientes. A capacidade intelectual do indivíduo pode ser potencialmente ampliada quando as modernas ferramentas colaborativas o colocam em contato com o saber acumulado na nuvem computacional.

Hoje, é irrelevante questionar se os dispositivos móveis prejudicam o aprendizado. Para a sociedade atual, não são mais novidades que poderão mudar a 
forma como trabalhamos, eles já fazem parte de nosso cotidiano neste século XXI. Saber utilizar as tecnologias de informação de modo produtivo pode ser um importante diferencial na carreira de um profissional e o problema, portanto, está em como adaptar as metodologias tradicionais de ensino para que elas possam tirar proveito das ferramentas digitais de colaboração.

\title{
O ALUNO, A sALA de AULA E O PROFESSOR CONTEMPORÂNEOS: UMA RELAC̣ÃO INSTÁVEL
}

A maioria dos alunos de hoje pertence à Geração Y ou Geração do Milênio (nascidos até 2004) e à geração posterior (nascidos a partir de 2005), ainda sem um nome definido. Segundo Scott Keeter e Paul Taylor, membros do quadro superior do Pew Research Center, a Geração Y é

A primeira na história humana que considera comportamentos como tuitar e enviar mensagens de texto, junto com websites como Facebook, Youtube, Google e Wikipedia, não como inovações impressionantes da era digital, mas como partes diárias de suas vidas sociais e de sua busca por entendimento (Keeter e Taylor, 2009).

Neil Howe e William Strauss definem as características dos jovens desta geração:

\begin{abstract}
Os membros da Geração do Milênio] nasceram em uma época em que as pessoas começaram a expressar atitudes mais positivas em relação às crianças. [...] Comparados com os membros da Geração X, os jovens de hoje são mais otimistas em relação ao mundo em que estão crescendo. Nove em dez se descreve como "feliz", "confiante" e "positivo". [...] Eles são jogadores cooperativos. Dos uniformes escolares, ao aprendizado em equipe e ao serviço comunitário, os membros desta geração estão gravitando em torno das atividades em grupo. [...] Eles aceitam a autoridade. A maior parte dos adolescentes afirmam se identificar com os valores de seus pais e noventa por cento deles afirma confiar e se sentir próximo deles. [...] Os jovens de hoje acreditam no futuro e enxergam a si próprios como à frente das outras gerações. Eles exibem fascinação e domínio das novas tecnologias. (Howe e Strauss, 2000)
\end{abstract}

Ao observarmos os alunos contemporâneos em sala de aula, confirmamos a naturalidade com que são capazes de manterem-se conectados aos acontecimentos cotidianos por meio de inúmeros recursos tecnológicos. Acostumados a dividir sua atenção entre várias atividades simultâneas, muitas vezes são capazes de surpreender membros de gerações anteriores.

O contato permanente com mecanismos de buscas, repositórios de informação e redes sociais transformou jovens naturalmente curiosos em fervorosos questionadores.

No dia a dia escolar, os alunos mostram comportamentos ditos hiperativos e intermitentes, preocupando pais e professores. Querem estar no controle daquilo em que 
se envolvem e não têm paciência para ouvir um professor explicar um mundo que ele já conhece com suas próprias convicções. Como se o aluno fosse digital e a escola analógica (Fonseca e Alquéres apud Ferraz, 2011).

O modelo de sala de aula atual, fruto de uma época em que tecnologias digitais não estavam amplamente disponíveis, tornou-se incompatível com os alunos que a frequentam. "Nossas instituições de ensino mudaram muito mais lentamente que os modos de aprendizado inventivos, colaborativos e participativos oferecidos pela internet e por uma gama de tecnologias móveis contemporâneas." (Davidson e Goldberg, 2009). Em seu cotidiano, os jovens saciam sua curiosidade através do acesso constante às fontes de informação digitais. Entretanto, mesmo no ambiente acadêmico de cursos mais recentes, os alunos encontram uma estrutura ultrapassada onde, enfileirados em silêncio em suas carteiras, devem focar toda a sua atenção no discurso do professor, sem acesso aos recursos interativos que fazem parte de seu cotidiano extraclasse.

Além da estrutura ultrapassada dos métodos de ensino, a infraestrutura das salas de aula também se mostra inadequada para o uso das ferramentas colaborativas. Em seu artigo Preparing teachers for technology integration: creating a culture of inquiry in the context of use (Preparando professores para a integração tecnológica: criando uma cultura inquisidora no contexto de uso), as professoras canadenses Michelle Jacobsen, Pat Clifford e Sharon Friesen descrevem algumas das possíveis causas para as dificuldades encontradas no ambiente educacional contemporâneo:

Aqueles em posições de liderança acadêmica geralmente possuem menos experiência com tecnologia que seus professores e, assim, nem sempre são capazes de prover o suporte necessário para as mudanças requeridas para a infusão efetiva de tecnologia nos locais de ensino. Quase sempre por padrão, visões de uso de tecnologia no ensino e na aprendizagem geralmente são criadas por especialistas em Tecnologia da Informação que não são educadores. Projetos de redes e sistemas de acesso por estudantes são determinados pelo que é padrão, fácil de manter e monitorar, e não por aquilo que é mais adequado para a educação (Jacobsen, Clifford e Friesen, 2002)

Quando os alunos se deparam com um ritmo diferente daquele imposto pelo seu cotidiano, muitos sentem-se desmotivados. Eles necessitam de estímulos e desafios adequados a uma era de ubiquidade tecnológica e precisam de professores com quem possam dialogar em pé de igualdade. Entretanto, grande parte dos profissionais de ensino passaram por uma formação ainda considerada convencional, desprovida das tecnologias contemporâneas que são imprescindíveis para o ingresso no mercado de trabalho. Segundo a Dra. Maria Cândida Moraes, isso é causa de restrições a uma formação crítica e criativa:

Embora quase todos percebam que o mundo ao redor está se transformando de forma contínua apresentando resultados cada vez mais preocupantes em todo o mun- 
do, a grande maioria dos professores continua privilegiando a velha maneira como foram ensinados, reforçando o velho ensino, afastando o aprendiz do processo de construção do conhecimento que produz seres incompetentes, incapazes de criar, pensar, construir e reconstruir conhecimento (Moraes, 1997, p.16).

A curiosidade dos jovens alunos de hoje não é diferente daquela dos jovens de gerações anteriores - o que muda em ritmo cada vez mais acelerado é a disponibilidade de novas tecnologias que permitem o acesso a uma quantidade de informação que cresce de forma exponencial. Afirmar simplesmente que o aluno contemporâneo não consegue manter sua atenção no professor é esquecer que, ontem, os alunos se distraiam durante as aulas trocando bilhetes às escondidas com meia dúzia de colegas, liam seus gibis escondidos nos livros didáticos e cochichavam sempre que os professores viravam as costas para escrever no quadro negro.

Esses comportamentos naturais não são diferentes dos comportamentos dos jovens atuais. Os bilhetes foram substituídos pelos aplicativos de mensagens instantâneas, os gibis foram trocados pelo vasto conteúdo de entretenimento interativo disponível na internet e os cochichos cederam seus lugares às redes sociais acessadas a partir dos telefones inteligentes. Entretanto, enquanto os alunos evoluem rapidamente na medida em que novas tecnologias são introduzidas, a sala de aula e os métodos de ensino permanecem inalterados. A impressão de que o problema no ensino atual está na falta de interesse e capacidade de foco dos alunos mostra-se equivocada quando percebemos que, na prática, os jovens são extremamente adaptáveis aos avanços tecnológicos da sociedade - é a sala de aula que tem se mostrado incapaz de acompanhar o ritmo acelerado dos alunos que a frequentam.

Há, por outro lado, um esforço de muitos professores para acompanhar a forma como seus alunos se comunicam. Vários deles publicam conteúdo de apoio em ferramentas colaborativas e mantêm contato com seus alunos através das redes sociais. Entretanto, os serviços digitais funcionam como um canal à parte do meio acadêmico convencional, um ambiente virtual para transmitir conteúdo adicional, não essencial à condução das disciplinas. Para esses professores, smartphones, tablets e computadores portáteis são fontes de distração que impedem que os alunos fixem sua atenção ao conteúdo lecionado e insistem que seus estudantes os usem como ferramentas de estudo apenas quando não estão em aula.

Dessa forma, cada aula permanece uma atividade isolada, em que o professor assume o papel centralizador da informação enquanto demanda a atenção de seus alunos. Ainda assim, as tecnologias digitais de comunicação aumentaram consideravelmente o contato entre professores e alunos nos horários extraclasse. Segundo os professores Mark Piwinski, Mary Leidman e Mathew McKeague, da Universidade da Pennsylvania, “apesar de estudos indicarem que há benefícios sig- 
nificativos na comunicação expandida entre docentes e estudantes, ela cria novas demandas enquanto obrigações e expectativas tradicionais se mantêm” (2010).

Pesquisando o impacto do Facebook na comunicação entre professores e alunos, Piwinski e Leidman afirmam que:

[...] os estudantes não usam o contato virtual de um modo muito diferente dos encontros cara-a-cara. Entretanto, os estudantes relataram que ficam mais satisfeitos com as interações online do que com aquelas presenciais. Hickerson e Gigolo (2009) argumentam que certas tecnologias, como as mensagens instantâneas, por exemplo, melhoram as experiências educacionais dos estudantes e melhoram a qualidade e a quantidade das interações com seus instrutores. [...] Os dados também sugerem que as mensagens instantâneas não reduzem as outras formas de comunicação. De um modo geral, estudantes e instrutores creem que elas funcionam com uma importante ferramenta educacional (2009)

Os professores da atualidade precisam ser flexíveis para enfrentar os desafios de uma era em que seus alunos têm acesso ilimitado à informação. Mais do que simplesmente instruir os estudantes, eles agora precisam convencê-los a focar sua atenção nas tarefas demandadas, ensiná-los a lidar com as ferramentas de pesquisa e colaboração e ajudá-los desenvolver o pensamento crítico necessário para enfrentar um mundo competitivo em desenvolvimento acelerado. Um professor contemporâneo não pode mais se basear apenas em seu conhecimento acadêmico; ele precisa entender como seus alunos pensam para se antecipar às suas necessidades e, assim, prepará-los para lidar com tecnologias que ainda não foram desenvolvidas no exercício de carreiras que ainda não existem.

\section{CONCLUSÃO: A EVOLUC̣ÃO DA SALA DE AULA}

É evidente que vivemos, como em outras épocas de nossa história, um momento de transição que está mudando nossas relações com o ambiente, com o mercado, com a sociedade de maneira geral e, até mesmo, com nossos círculos familiares e de amizade. Segundo o Dr. Sugata Mitra, professor de Tecnologia da Educação na Universidade de Newcastle, uma das consequências mais importantes destas mudanças é a obsolescência do método tradicional de ensino. Mitra afirma que muitas das habilidades ensinadas nas salas de aula serão irrelevantes para as profissões exercidas nas próximas décadas e propõe um novo currículo como solução:

O currículo só precisa de três elementos. Interpretação de textos é a habilidade mais crítica neste ponto da história para uma geração que lerá em telas para o resto de suas vidas. Habilidade de busca e recuperação de informação - se as pessoas souberem o que são palavras-chave ou se devem seguir um link, terão uma habilidade 
importante. Se a aritmética é uma habilidade ultrapassada, esta é a que irá substituí-la. Finalmente, se uma criança sabe escrever e buscar informação, como ensiná-la a acreditar? Em nossas mentes adultas, cada um de nós tem um pequeno mecanismo que nos permite acreditar. Às vezes dizemos que algo é óbvio, às vezes é alguém que nos diz. Algumas vezes achamos que algo é besteira. O que é este mecanismo que existe em nossas mentes? Quão cedo na vida de uma criança podemos implantar este mecanismo em sua mente? Se pudermos fazer isso realmente cedo, então teremos armado essa criança contra a doutrina - não apenas a doutrina religiosa, mas em todas as suas formas. Acredito que o trabalho do educador neste mundo saturado de informação é dar às crianças uma armadura contra a doutrina, da mesma forma que outras gerações ensinaram seus filhos a usar uma espada ou a cavalgar (2011)

Em muitas salas de aula, as mesmas tecnologias móveis que fazem parte do cotidiano dos jovens são barradas, tratadas como fontes de distração incapazes de agregar vantagens aos métodos de ensino consagrados. Aos alunos, muitas vezes, só resta o aprendizado autodidata - experimentando as ferramentas digitais, eles as integram às suas vidas extraclasse e, com pouco ou nenhum apoio formal da academia, levam-nas para o ambiente profissional.

Sob a ótica acadêmica, esta é uma situação que carece de revisão. A cada ano, universidades formam novos profissionais que aprendem por conta própria a lidar com muitas das ferramentas digitais que passarão a utilizar em seus cotidianos. Este conhecimento está, cada vez mais, sendo acumulado fora das salas de aula e são passados adiante de maneira informal. O pesquisador Guilherme de Almeida Reis, após uma série de pesquisas de campo com profissionais da área de arquitetura da informação, destaca o impacto desse aprendizado informal no mercado:

A primeira pesquisa de campo retratou um profissional jovem, que vive nos grandes centros metropolitanos, com formação predominante na área de Humanas e que desenvolveu seus conhecimentos sobre Arquitetura de Informação de maneira autodidata. Quase metade deles não segue qualquer metodologia nos seus projetos e, entre os que seguem, a maioria utiliza uma metodologia própria. [...] A formação autodidata que esses profissionais têm adotado, devido à falta de alternativas, não tem se mostrado eficiente (2007, p. 9).

O meio educacional em nosso país deve considerar a formalização do uso das tecnologias que estão cada vez mais integradas às vidas dos alunos. Um ambiente acadêmico inovador, capaz de explorar o uso de metodologias participantes, do conhecimento interdisciplinar e, principalmente, do pensamento criativo como meios de produção, é imprescindível para que os futuros profissionais aprendam a lidar de modo crítico com a tecnologia que estará disponível em seu cotidiano.

As ferramentas colaborativas da atualidade complementam muito bem as metodologias interdisciplinares que muitas escolas e cursos universitários come- 
çam a aplicar. Além disso, a maior parte dos dispositivos móveis atuais possuem inúmeros sensores capazes de obter dados valiosos a respeito do ambiente que nos rodeia - esses sensores podem ser usados como ferramentas inovadoras para a geração de conhecimento, permitindo que cada aluno tenha acesso a um completo laboratório portátil para a realização de inúmeras experiências educacionais.

Ao combinar as metodologias interdisciplinares com as tecnologias digitais disponibilizadas pelos dispositivos móveis da atualidade, o processo produtivo dos alunos pode ser otimizado, levando não apenas a resultados de qualidade, mas, acima de tudo, a uma melhor preparação para um mercado profissional cada vez mais exigente. Ao aprender a lidar de modo crítico com os avanços tecnológicos que nos rodeiam, os jovens reunirão subsídios poderosos para moldar nossa sociedade de um modo mais consciente.

Começamos a viver a realidade de uma grande inteligência coletiva.

Com o crescimento da conectividade, largura de banda e velocidade dos computadores, estamos começando a vislumbrar uma visão da biosfera como um processador de dados recapitulado, mas um milhão de vezes mais veloz e com milhões de agentes com intelecto humano (nós mesmos) (1993).

Ensinar nossos alunos a lidar com o grande fluxo de conhecimento de forma crítica é um passo importante na criação de um saber verdadeiramente global.

\section{REFERÊNCIAS}

JACOBSEN, M.; CLIFFORD, P.; FRIESEN, S. Preparing teachers for technology integration: Creating a culture of inquiry in the context of use. Contemporary Issues in Technology and Teacher Education. Norfolk, VA: AACE, 2002.

DAVIDSON, C.; GOLDBERG, D. The future of learning: Institutions in a Digital Age. Cambridge, MA: The MIT Press, 2009.

FERRAZ, C.R. O aluno do século XXI - Desafios e perspectivas para o ensino de ciência e biologia. Brasil Escola. 2011. Disponível em <http://meuartigo.brasilescola.uol.com.br/educacao/o-aluno-seculo-xxidesafios-pespectivas-para-ensino-. htm>. Acesso em: maio 2012.

FILATRO, A. Design Instrucional Contextualizado. São Paulo: SENAC, 2004.

GONDIM, S. M .G. Perfil profissional e mercado de trabalho: relação com a formação acadêmica pela perspectiva de estudantes universitários. Estudos de Psicologia: , São Paulo: PUC-Campinas, v. 7. 2002.

HOWE, J. The Rise of Crowdsourcing. Wired Magazine Online. 2006. Disponível em <http://www.wired.com/wired/archive/14.06/crowds.html>. Acesso em: novembro de 2008. 
KEETER, S.; TAYLOR, P. The Millennials. Pew Research Center Website. 2009. Disponível em: <http://www.pewresearch.org/2009/12/10/the-millennials/>. Acesso em: nov. de 2010.

LEIDMAN, M. B.; PIWINSKI, M. J. The Perpetual Professor in the 21st Century. Indiana, PA: Department of Communications Media, Indiana University of Pennsylvania, 2009.

PIWINSKI, M.J.; LEIDMANN, M.B.; MCKEAGUE, M. Technology's Impact on Student - Faculty Interaction: Issues for Collective Bargaining. Journal of Collective Bargaining in the Academy, Berkeley, v. 2, artigo 3. 2010. Disponível em: <http://thekeep.eiu.edu/jcba/vol2/iss1/3>. Acesso em: set. 2011.

MITRA, S. Future Learning Short Documentary. LA: Good. 2011. Entrevista em vídeo (12:50 min.). Disponível em: <http://www.youtube.com/watch?v=qC_T9ePzANg>. Acesso em: jun. 2012.

MORAES, M. C. O paradigma emergente. Campinas: Papirus, 1997.

REIS, G. A. Centrando a Arquitetura da Informação no Usuário. São Paulo, 2007. Dissertação de Mestrado - Escola de Comunicação e Artes, Universidade de São Paulo. VINGE, V. The Coming Technological Singularity. Garches: Feedbooks, 1993. 
